ISSN 0103-8478

\title{
Criptococose cutânea associada à severa infestação por Sarcoptes sp. e Demodex sp. em um cão
}

\author{
Cutaneous cryptococcosis associated with severe infestation by Sarcoptes sp. \\ and Demodex sp. in a dog
}

\section{Danieli Brolo Martins ${ }^{\mathrm{I}}$ Maria Anastásia Johann Deckmann ${ }^{\mathrm{II}}$ Vitor da Rocha Sperotto ${ }^{\mathrm{III}}$}

\section{- NOTA -}

RESUMO

Este trabalho descreve um caso de criptococose canina localizada na pele da região interdigital de um cão. Um cão de rua, sem raça definida, adulto jovem apresentava lesões pruriginosas, alopécicas e crostosas em toda extensão corpórea, e uma lesão ulcerada interdigital no membro pélvico esquerdo. A citologia aspirativa por agulha fina (CAAF) da lesão interdigital demonstrou um processo inflamatório acrescido de organismos leveduriformes compatíveis com Cryptococcus sp. Efetuou-se, a seguir, a cultura fúngica, que ratificou o resultado da CAAF. O paciente também apresentou diagnóstico positivo para Sarcoptes $s p$. e Demodex sp. Cryptococcus sp. é o agente etiológico da criptococose, uma doença infecciosa oportunista que acomete o homem, animais domésticos e silvestres. A provável imunidade baixa do cão, neste estudo, pode ter sido um fator desencadeante para o desenvolvimento da doença. A criptococose em caninos, apresentada na forma cutânea, é incomum, o que justifica a relevância deste relato.

Palavras-chave: imunossupressão, infecção fúngica oportunista, úlcera cutânea, citologia aspirativa por agulha fina, canino.

\section{ABSTRACT}

The aim of this study was to report a case of cutaneous cryptococcosis located in the interdigital skin of a dog. A young adult mongrel dog presented pruritic alopecic crusty lesions throughout corporeal extension and an ulcerated lesion in the interdigital region of the left pelvic limb. A fine needle aspiration cytology (FNAC) of the interdigital lesion showed an inflammatory process plus yeast organisms similar to Cryptococcus sp. A mycological culture was carried out confirming the results of FNAC. The patient also had positive diagnosis to Sarcoptes sp. and Demodex sp.. Cryptococcus sp. is the etiologic agent of cryptococcosis, an infectious opportunistic disease that affects humans, domestic and wild animals. The probable low immunity of the dog, in this study, may have been a triggering factor for the development of the disease. Canine cutaneous cryptococcosis is unusual, which explains the relevance of this report case.

Key words: Immunosuppression, opportunistic fungal infection, skin ulcer, fine needle aspiration cytology, canine.

A criptococose é uma doença adquirida do ambiente contaminado, causada por uma levedura encapsulada, Cryptococcus sp., mais comumente observada em gatos do que em cães (MCGILL et al., 2009). O tecido cutâneo pode se tornar infectado quando organismos fúngicos contaminam ou colonizam a superfície epidérmica ou os folículos pilosos. A quebra da barreira epitelial pode permitir a entrada e disseminação de diferentes fungos (OUTERBRIDGE, 2006).

O sistema imune do hospedeiro está envolvido na patogênese de várias doenças cutâneas (FOSTER, 2004). Nos gatos, a infecção cutânea por criptococose ocorre preferencialmente na pele da cabeça e pescoço. O envolvimento cutâneo geralmente manifesta-se como nódulos firmes que aumentam de volume rapidamente e depois ulceram e exsudam (PENNISI et al., 2013). Contudo, em cães, a principal via de infecção é a inalatória, produzindo uma rápida disseminação a diferentes sistemas, incluindo o sistema nervoso central (SNC). Já, as lesões cutâneas aparecem em um número reduzido de pacientes caninos (CASTELLÁ et al., 2008).

IDepartamento de Medicina Veterinária, Setor de Clínica e Cirurgia, Escola de Veterinária e Zootecnia, Universidade Federal de Goiás (UFG), CP 131, 74001-970, Goiânia, GO, Brasil. E-mail: vetdanielimartins@yahoo.com.br. Autor para correspondência.

IICurso de Medicina Veterinária, Universidade de Cruz Alta (Unicruz), Cruz Alta, RS, Brasil.

IIICentro de Ciências da Saúde, Laboratório de Microbiologia Veterinária, Unicruz, Cruz Alta, RS, Brasil. Recebido 22.08.13 Aprovado 22.01.14 Devolvido pelo autor 22.05.14 CR-2013-1128.R3 
A criptococose cutânea primária é de rara ocorrência, uma vez que as lesões cutâneas geralmente são acompanhadas da infecção sistêmica. Há evidências de que a infecção cutânea primária por Cryptococcus sp. ocorra por inoculação direta do micro-organismo em locais de dano celular ou trauma (KHODAKARAM-TAFTI \& DEHGHANI, 2006; PAU et al., 2010). Assim, este trabalho descreve um caso de criptococose localizada na pele da região interdigital de um cão com escabiose e demodicose generalizadas, cujo diagnóstico deu-se através da citologia aspirativa por agulha fina (CAAF), sendo posteriormente ratificado pela cultura fúngica. A criptococose em caninos apresentada na forma cutânea é incomum, o que justifica a relevância desse relato.

Um cão de rua, fêmea, sem raça definida, foi adotado e trazido para atendimento por apresentar baixo estado corporal, prurido intenso, alopecia, eritema e lesões em toda superfície corporal com crostas (Figura 1A), além de uma lesão ulcerativa na região interdigital do membro pélvico esquerdo (Figura 1B). Apesar disso, não havia linfoadenomegalia. Foram solicitados, inicialmente, exames bioquímicos (alanina aminotransferase, fosfatase alcalina, creatinina e ureia), hemograma, parasitológico e citológico de pele, além de CAAF na lesão do membro. Havia, inicialmente, suspeita de dermatopatia por Sarcoptes sp. pela apresentação clínica.

O hemograma apresentou anemia normocítica normocrômica e leucocitose por neutrofilia, além de linfopenia. Nos exames bioquímicos, não houve alterações. O raspado de pele revelou a presença de ácaros Sarcoptes sp. e Demodex sp. O citológico de pele revelou células inflamatórias degeneradas e bactérias. A CAAF da lesão revelou a presença moderada de neutrófilos degenerados e macrófagos ativados, além de eventuais bactérias e moderada quantidade de leveduras fúngicas compatíveis com Cryptococcus sp. (Figura 1C). A seguir, realizou-se ratificação do resultado da CAAF com coloração de nanquim (Figura 1D) e cultura fúngica (Cryptococcus sp.). O raio-x torácico realizado após o diagnóstico citológico não evidenciou alterações no padrão pulmonar do paciente. Somam-se a isso, movimentos respiratórios e ausculta pulmonar dentro da normalidade.

Pelo estado geral do paciente, instituiuse medicação inicial acaricida (moxidectina, 0,2mg $\mathrm{kg}^{-1}$, via subcutânea, a cada 72 horas) e bactericida (cefalexina, 25mg $\mathrm{kg}^{-1}$, via oral, BID), além de

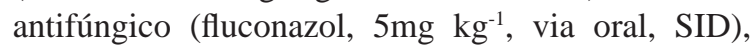
limpeza da ferida e uso de colar elizabetano. A moxidectina foi utilizada por dois meses consecutivos, sendo que, ao final desse período, o paciente apresentou ausência de ambos os ácaros em dois raspados realizados com intervalo de 10 dias. A cefalexina foi utilizada por um mês, percebendo-se, ao final desse tempo, melhora da piodermite.

Contudo, somente após um mês do início do tratamento com o antifúngico, a proprietária retornou para revisão clínica, quando foi possível observar que a lesão havia aumentado discretamente de tamanho. Nova CAAF foi feita, e observaram-se estruturas compatíveis com o fungo anteriormente visualizado. Diante disso, o tratamento foi alterado para itraconazol (10mg kg-1, SID), e na lesão foi realizado curativo com pomada tópica a base de cetoconazol. Ao final de duas semanas do uso do itraconazol, observou-se gradual redução no tamanho da lesão e, após mais duas semanas, houve total cicatrização. Nesse momento, nenhuma estrutura fúngica foi visualizada na CAAF, bem como, não houve crescimento na cultura fúngica. O tratamento, porém, continuou por mais um mês após a cura clínica.

A criptococose cutânea é de difícil diagnóstico do ponto de vista clínico, porque as lesões de pele não são patognomônicas, variando de nódulos a úlceras e placas. Além disso, a doença pode resultar em lesões similares a outras doenças, como a celulite bacteriana (ALLEGUE et al., 2007). Nesse caso em especial, a presença de várias alterações de pele causadas pelas doenças concomitantes (demodicose, escabiose e piodermite secundária) em um animal sem histórico definido, pois era um cão de rua, tornaram a identificação da lesão ulcerada desafiadora.

Dessa forma, é de grande interesse a investigação de lesões cutâneas atípicas por diferentes métodos, como a CAAF. Os autores enfatizam a importância da CAAF como uma alternativa rápida e eficaz para o reconhecimento in vivo de estruturas fúngicas como Cryptococcus sp., tanto em cães quanto em gatos. É um método simples e de baixo custo, pois não envolve equipamentos sofisticados (MARTINS et al., 2008; MARTINS et al., 2011).

Todavia, ainda que o exame citológico demonstre o organismo na maioria dos casos, a realização da cultura fúngica continua sendo uma técnica mais sensível (VORATHAVORN et al., 2013), sendo fundamental para a confirmação dos resultados da CAAF. Apesar do presente relato não ter caracterizado a espécie do agente envolvido na lesão, é possível que haja relação com $C$. neoformans, pois, além de $\boldsymbol{C}$. neoformans var. neoformans e $\boldsymbol{C}$. neoformans var. grubii já terem sido identificados na região (MARTINS et al., 2008; MARTINS et al., 2011), o animal encontrava-se em uma situação 


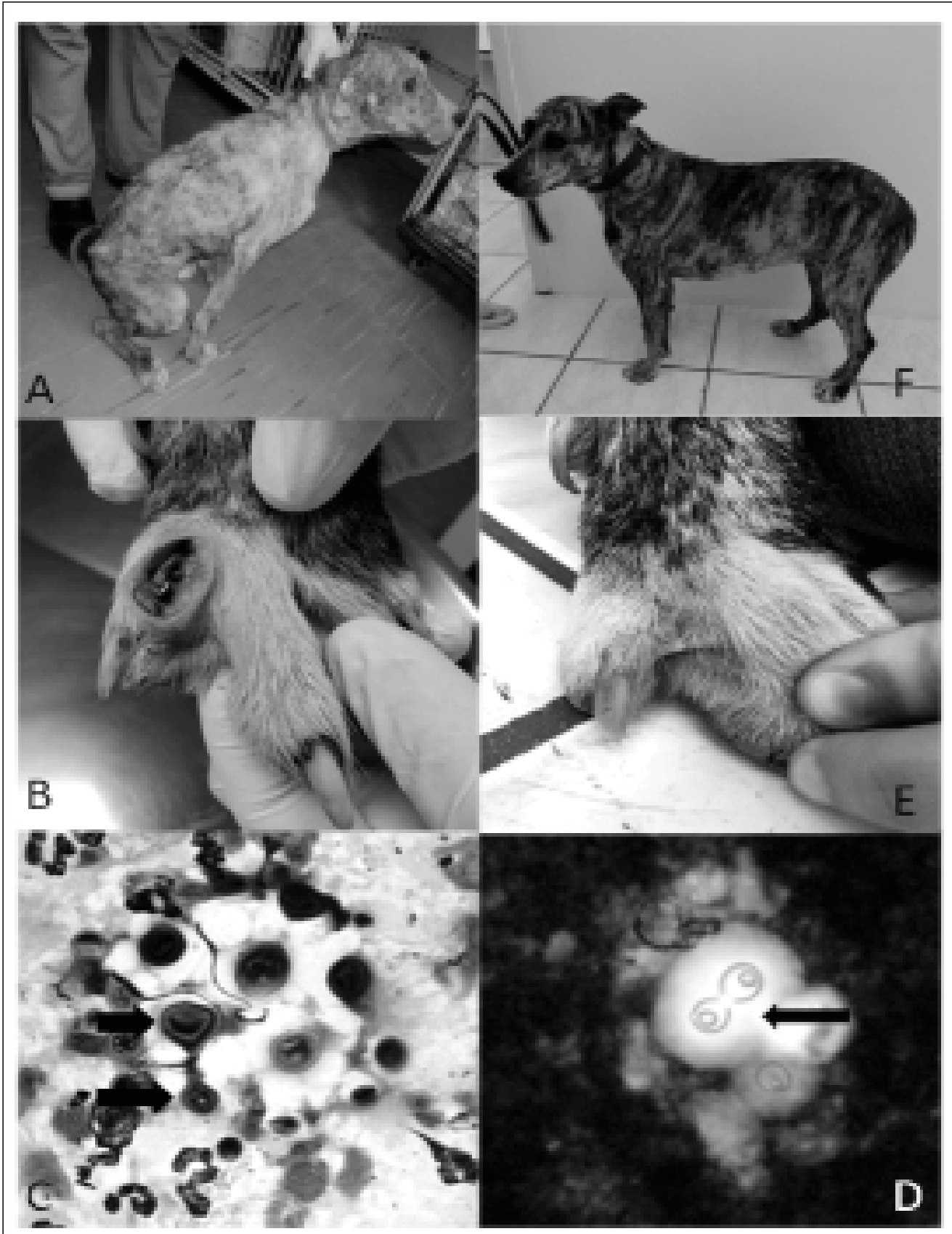

Figura 1 - Cão com criptococose cutânea. A) Paciente apresentando baixo estado corporal, pelagem opaca e escassa, eritema e alopecia; B) aspecto ulcerado da lesão no MPE; C) citologia aspirativa por agulha fina evidenciando leveduras fúngicas compatíveis com Cryptococcus sp. (Panótico rápido, 1000x); D) brotamento de leveduras (seta) demonstrado pela coloração nanquim (1000x); E) área de cicatrização da lesão*; F) paciente em bom estado corporal e sem lesões cutâneas decorrentes de demodicose, escabiose e criptococose* (*E, F- um ano após o tratamento).

de imunossupressão (BLANCO \& GARCIA, 2008; MCGILL et al., 2009).

Em pacientes veterinários, há evidências limitadas de uma relação causal entre uma desordem imunodeficiente aparente e o desenvolvimento de uma doença cutânea (FOSTER, 2004). Apesar dos parâmetros que predispõem ao aparecimento de demodicose não serem completamente compreendidos, sabe-se que uma alteração na resposta imunomediada por células, como os linfócitos, é um fator relevante (SINGH et al., 2010). Nesse sentido, o paciente relatado apresentava uma 
evidente linfopenia, além de outros fatores que poderiam potencializar a imunossupressão do animal, como a má nutrição e a escabiose. Já, a leucocitose por neutrofilia é decorrente da infecção bacteriana secundária da pele.

A forma cutânea primária de criptococose pode ocorrer indiferentemente do paciente ser imunocompetente ou imunocomprometido (CHRISTIANSON et al., 2003). As células T CD4+, no entanto, são críticas para o controle do fungo (KWON-CHUNG et al., 2000). Cães com demodicose generalizada, como o cão relatado, apresentam um número mais baixo de células $\mathrm{T}$ CD4+, quando comparados a animais com demodicose localizada ou controles sadios (SINGH et al., 2010).

A escolha do fluconazol deu-se, em um primeiro momento, devido ao risco de o paciente desenvolver a forma disseminada da doença, com especial risco ao SNC, além de demandar um período mais curto de tratamento, quando comparado ao itraconazol (O'BRIEN et al., 2006). A escolha do antifúngico, no entanto, depende da extensão da doença e da imunocompetência do hospedeiro (CHRISTIANSON et al., 2003). Todavia, algumas cepas de Cryptococcus apresentam resistência a determinados fármacos, em especial ao fluconazol (VORATHAVORN et al., 2013). Tais fatos podem ter influenciado na resposta terapêutica apresentada pelo paciente frente ao fluconazol, sendo necessária sua substituição para o itraconazol.

Apesar do fluconazol ter boa ação em micoses superficiais, o itraconazol age bem tanto em micoses superficiais quanto profundas da pele (AMICHAI \& GRUNWALD, 1998). O itraconazol é eficaz no tratamento de uma grande variedade de micoses superficiais, por se acumular nos ceratinócitos e atingir altas concentrações na secreção sebácea e nos pelos (KORTING \& SCHÖLLMANN, 2009).

Um ano após o fechamento do caso, o cão encontrava-se em bom estado corporal e sem lesões cutâneas relacionadas à demodicose, escabiose e criptococose (Figura 1E, 1F). Durante esse período, o paciente não apresentou nenhum tipo de recidiva da enfermidade fúngica.

É importante que se investiguem lesões cutâneas ulceradas detalhadamente, pois, como visto neste caso, agentes pouco comuns, como fungos, podem estar relacionados. Portanto, esse relato reforça o risco de criptococose em animais debilitados e, ainda, chama a atenção para formas de aparecimento atípicas da doença. A utilização da CAAF para o diagnóstico permitiu o reconhecimento precoce do agente envolvido. A escolha do antifúngico deve ser bem orientada, pois a ação pode não ser a esperada, de acordo com a forma apresentada da enfermidade, ocasionando demora na cura do paciente.

\section{COMITÊ DE ÉTICA E BIOSEGURANÇA}

Declaração dos autores - O relato foi executado com animal atendido na rotina do Hospital Veterinário da Unicruz, e não foi parte de qualquer projeto, sendo apenas um relato de caso clínico. Os autores ficam à disposição para quaisquer esclarecimentos sobre o trabalho.

\section{REFERÊNCIAS}

ALLEGUE, F. et al. Primary cutaneous cryptococcosis presenting as a whitlow. Acta Dermato Venereologica, v.87, p.443-444, 2007. Disponível em: <http://www.medicaljournals.se/acta/con tent/?doi=10.2340/00015555-0275>. Acesso em: 15 ago. 2013. doi: $10.2340 / 00015555-0275$.

AMICHAI, B.; GRUNWALD, M.H. Adverse drug reactions of the new oral antifungal agents - terbinafine, fluconazole, and itraconazole. International Journal of Dermatology, v.37, p.410-415, 1998.

BLANCO, J.L.; GARCIA, M.E. Immune response to fungal infections. Veterinary Immunology and Immunopathology, v.125, p.47-70, 2008. Disponível em: <http://www.sepeap.org/ archivos/pdf/10806.pdf> Acesso em: 10 ago. 2013. doi: 10.1016/j. vetimm.2008.04.020.

CASTELLÁ, G. et al. Criptococosis y animales de compañía. Revista Iberoamericana de Micología, v.25, p.19-24, 2008. Disponível em: <http://reviberoammicol.com/2008-25/S19S24. pdf $>$. Acesso em: 15 ago. 2013

CHRISTIANSON, J.C. et al. Primary cutaneous cryptococcosis in immunocompetent and immunocompromised hosts. Medical Mycology, v.41, p.177-188, 2003. Disponível em: <http:// informahealthcare.com/doi/abs/10.1080/1369378031000137224>. Acesso em: 17 ago. 2013. doi:10.1080/1369378031000137224.

FOSTER, A.P. Immunomodulation and immunodeficiency. Veterinary Dermatology, v.15, p.115-126, 2004. Disponível em: <http://onlinelibrary.wiley.com/doi/10.1111/j.1365-3164.2004. 00363.x/abstract>. Acesso em: 15 ago. 2013. doi: 10.1111/j.13653164.2004.00363.x

KHODAKARAM-TAFTI, A.; DEHGHANI, S. Cutaneous cryptococcosis in a donkey. Comparative Clinical Pathology, v.15, p.271-273, 2006. Disponível em: <http://link.springer. com/content/pdf/10.1007\%2Fs00580-006-0641-3.pdf\#page-1>. Acesso em: 15 ago. 2013. doi: 10.1007/s00580-006-0641-3.

KORTING, H.C.; SCHÖLLMANN, C. The significance of itraconazole for treatment of fungal infections of skin, nails and mucous membranes. Journal of the German Society of Dermatology, v.7, p.11-19, 2009. Disponível em: <http:// onlinelibrary.wiley.com/doi/10.1111/j.1610-0387.2008.06751.x/ abstract>. Acesso em: 15 ago. 2013. doi: 10.1111/j.16100387.2008.06751.x.

KWON-CHUNG, K.J. et al. Cryptococcosis: clinical and biological aspects. Medical Mycology, v.38, supl. 1, p.205- 
213, 2000. Disponível em: <http://informahealthcare.com/doi/ abs/10.1080/mmy.38.s1.205.213?journalCode=mmy>. Acesso em: 16 ago. 2013. doi: 10.1080/mmy.38.s1.205.213.

MARTINS, D.B. et al. Diagnóstico de criptococose canina pela citologia aspirativa por agulha fina. Ciência Rural, v.38, p.826829, 2008. Disponível em: <http://www.scielo.br/pdf/cr/v38n3/ a39v38n3.pdf>. Acesso em: 15 ago. 2013. doi: 10.1590/S010384782008000300039 .

MARTINS, D.B. et al. Massive cryptococcal disseminated infection in an immunocompetent cat. Veterinary Dermatology, v.22, p.232-234, 2011. Disponível em: <http://onlinelibrary.wiley. com/doi/10.1111/j.1365-3164.2010.00948.x/abstract>. Acesso em: 15 ago. 2013. doi: 10.1111/j.1365-3164.2010.00948.x.

MCGILL, S. et al. Cryptococcosis in domestic animals in Western Australia: a retrospective study from 1995-2006. Medical Mycology, v.47, p.625-639, 2009. Disponível em: $<$ http://informahealthcare.com/doi/abs/10.1080/13693780802 512519?journalCode=mmy>. Acesso em: 17 ago. 2013 . doi: $10.1080 / 13693780802512519$.

O’BRIEN, C.R. et al. Long-term outcome of therapy for 59 cats and 11 dogs with cryptococcosis. Australian Veterinary Journal, v.84, p.384-392, 2006. Disponível em: <http://onlinelibrary.wiley. com/doi/10.1111/j.1751-0813.2006.00040.x/abstract>. Acesso em: 15 ago. 2013. doi: 10.1111/j.1751-0813.2006.00040.x.
OUTERBRIDGE, C.A. Mycologic disorders of the skin. Clinical Techniques in Small Animal Practice, v.21, p.128134, 2006. Disponível em: <http://www.journals.elsevierhealth. com/periodicals/ysvms/article/S1096-2867(06)00033-8/abstract>. Acesso em: 15 ago. 2013. doi:10.1053/j.ctsap.2006.05.005.

PAU, M. et al. Primary cutaneous cryptococcosis in an immunocompetent host. Mycoses, v.53, p.256-258, 2010. Disponível em: <http://onlinelibrary.wiley.com/doi/10.1111 j.1439-0507.2009.01707.x/full>. Acesso em: 15 ago. 2013. doi:10.1111/j.1439-0507.2009.01707.x.

PENNISI, M.G. et al. Cryptococcosis in cats: ABCD guidelines on prevention and management. Journal of Feline Medicine and Surgery, v.15, p.611-618, 2013. Disponível em: <http://jfm. sagepub.com/content/15/7/611.long>. Acesso em: 16 ago. 2013.

SINGH, S.K. et al. Determination of CD4+ and CD8+ T cells in the peripheral blood of dogs with demodicosis. Parasitology, v.137, p.1921-1924, 2010. Disponível em: <http://journals.cambridge. org/action/displayAbstract?fromPage $=$ online $\&$ aid $=7914014>$. Acesso em: 17 ago. 2013. doi: 10.1017/S0031182010000879.

VORATHAVORN, V.I. et al. Cryptococcosis as an emerging systemic mycosis in dogs. Journal of Veterinary Emergency and Critical Care, v.23, p.489-497, 2013. Disponível em: <http:// onlinelibrary.wiley.com/doi/10.1111/vec.12087/pdf>. Acesso em: 20 set. 2013. doi: 10.1111/vec.12087. 